\title{
Constitucionalización del Código General Disciplinario en Colombia
}

\section{Constitutionalization of the General Disciplinary Code in Colombia}

\author{
DOI: https://doi.org/10.17981/juridcuc.17.1.2021.19
}

Fecha de Recepción: 2020/06/26 Fecha de Aceptación: 2021/01/28

\author{
Maria Stephania Aponte García \\ Unidad Central del Valle del Cauca (UCEVA). Cali (Colombia) \\ maponte@uceva.edu.co
}

Jairo Vladimir Llano Franco (

Universidad Libre de Colombia. Cali (Colombia)

jairo.vladimirl@unilibre.edu.co

Giovanni Sánchez Espinosa

Universidad Libre de Colombia. Cali (Colombia)

Giovanni.sancheze@unilibre.edu.co

Para citar este artículo:

Aponte, M., Llano, J. \& Sánchez, G. (2021). Constitucionalización del Código General Disciplinario en Colombia. Jurídicas CUC, 17(1), 557-588. DOI: http://dx.doi.org/10.17981/juridcuc.17.1.2021.19

\section{Resumen}

El articulo se centra en la constitucionalización que trae consigo la entrada en vigor de la Ley 1952 de 2019 , mediante la cual se introduce en la vida jurídica el Código General Disciplinario, convirtiéndose en una herramienta estatal que en su primera parte reconoce la importancia de la implementación de los fines, principios y valores, para el correcto desempeño de funciones por parte de los funcionarios públicos y los procedimientos para cuando las conductas estén por fuera del ordenamiento jurídico, incluso, en la mismo la ley se amplía la posibilidad de vincular principios y derechos proveniente de los tratados y convenios internacionales por medio del bloque de constitucionalidad, permitiendo que los casos de mayor complejidad sean intervenidos desde el derecho internacional. El objetivo general de la investigación es analizar los cambios relevantes sucedidos con el nuevo régimen disciplinario. La metodología implementada se soporta en el método hermenéutico y la técnica de la interpretación, para exponer las razones por la cual el derecho disciplinario enmarca sus principios desde la Constitución; este tipo de métodos y técnicas se reconocen como cualitativos. Los resultados son la demostración de la constitucionalización y la incidencia leve del derecho internacional en el derecho disciplinario colombiano. Las transformaciones constitucionales y socio-jurídicas del código disciplinario posibilitan la eficiencia de los servidores públicos antes sus responsabilidades institucionales. Esta perspectiva de constitucionalización y de principios en el Código Disciplinario hace innovador este artículo.

Palabras clave: Código General Disciplinario; constitucionalización; derechos fundamentales principios constitucionales y derechos procesales

\section{Abstract}

The article focuses on the constitutionalization that brings with it the entry into force of Law 1952 of 2019, through which the General Disciplinary Code is introduced into legal life, becoming a state tool that in its first part recognizes the importance of the implementation of the purposes, principles and values, for the correct performance of functions by public officials and the procedures for when the conduct is outside the legal system, even in the same law the possibility of linking principles and rights from international treaties and conventions through the constitutionality block, allowing more complex cases to be intervened from international law. The general objective of the research: to analyze the relevant changes that occurred with the new disciplinary regime. The implemented methodology is supported by the hermeneutical method and the interpretation technique, to expose the reasons why disciplinary law frames its principles from the Constitution; these types of methods and techniques are recognized as qualitative. The results are the demonstration of the constitutionalization and the slight incidence of international law in Colombian disciplinary law. The constitutional and socio-legal transformations of the disciplinary code enable the efficiency of public servants before their institutional responsibilities. This perspective of constitutionalization and principles in the Disciplinary Code makes this article innovative.

Keywords: General Disciplinary Code; constitutionalization; fundamental rights constitutional principles and procedural rights 


\section{INTRODUCCIÓN}

Esta publicación es resultado del proyecto de investigación "Cambios cualitativos en el régimen disciplinario de los servidores públicos", cuyo objetivo general, el análisis de la Ley 1952 (2019), la cual expide el Código General Disciplinario-CGD, analizando su constitucionalización; que se encuentra plasmado de forma directa en la primera parte, y los principios rectores e indirecta en el resto del texto, permeando el derecho disciplinario de fundamentos constitucionales y exponiéndo la supremacía constitucional la cual caracteriza el enfoque Neo-constitucional y el Estado constitucional y democrático de derecho.

El proyecto de investigación por el cual se hace posible este articulo, plantea como problema de investigación el requerimiento de un cambio sustancial en el régimen disciplinario, toda vez que desde la vigencia de la Constitución (CP, 1991) se han expedido 3 Códigos Disciplinarios Únicos, en un intervalo de 29 años, lo cual permite vislumbrar la complejidad de su ejecución como disciplina del derecho, pero también admite establecer como era de vital importancia que el legislador incluyera dentro del régimen disciplinario los principios fundamentales que la Constitución establece y que han sido interpretados a la luz de la jurisprudencia de la Corte Interamericana de Derechos Humanos (CIDH) y la Corte Constitucional Colombiana, permitiendo que lo principios rectores sean un componente dinámico el cual se transforma con las actuaciones de la sociedad, y además debe buscar lograr una conducta pública ajustada al orden jurídico por parte de los servidores públicos; la eficacia de las nuevas instituciones disciplinarias depende en gran medida la credibilidad y confianza que la comunidad ofrezca a la Administración, de allí la relevancia de que el Código General Disciplinario sea establecido con respeto a la supremacía de la Constitución.

Este artículo se divide en tres partes, la primera considera la construcción del concepto de Derecho disciplinario desde la perspectiva constitucional, y la supremacía de la Constitución vinculada 
con la inclusión de los principios y los derechos fundamentales, enmarcados como pilares dentro del régimen disciplinario, el cual tiene como función regular el comportamiento de los funcionarios públicos, para garantizar el cumplimiento de los fines del Estado. En el segundo ítem se estudian los principios y derechos contenidos en la primera parte del Código General Disciplinario (CGD, 2019), el cual muestra claramente el proceso de constitucionalización, a lo que se incorpora la develación de la teoría detrás de la ley, cuyo enfoque general es el Neo-constitucionalismo y las particularidades teóricas encontradas en la argumentación jurídica de Alexy (2012) y el garantismo de Ferrajoli (2009).

También se incorpora el Derecho sustantivo que tiene relación con la estructura característica de los derechos fundamentales, y como el Derecho disciplinario es un garante en la preservación del Estado constitucional y democrático de derecho:

El Estado constitucional de cuño común europeo y atlántico se caracteriza por la dignidad humana como premisa antropológicacultural por la soberanía popular y la división de poderes, por los derechos fundamentales y la tolerancia [...] independencia de los tribunales (Häberle, 2018, p. 2).

Para el tercer y final ítem, se describen los principios procesales de la segunda parte del Código General Disciplinario, articulo 11 al articulo 22 (Ley 1952, 2019), analizando las garantías que tienen los investigados por vulnerar las funciones públicas encomendadas por medio de acciones ilegales y contrarias a los fines de su actividad laboral, interpretación que se realiza desde los pronunciamientos de la Corte Constitucional y los Tribunales Internacionales. Para el contexto institucional y jurídico colombiano el desarrollo del Derecho disciplinario ha sido paquidérmico y precario, por lo cual, es de esperarse que el Código General Disciplinario, en el ejercicio real de su vigencia, tenga el impacto esperado y tan necesitado como medida de acción contra los avatares del flagelo de la corrupción. Puede indicarse que la necesidad constructora del Derecho disciplinario está orientada a la constitucionalización del régimen disciplinario, 
como forma de lucha contra la corrupción, en relación directa con el cumplimiento de los fines estatales, utilizando como herramienta la facultad sancionadora, cuando el comportamiento de los funcionarios es contrario al ordenamiento jurídico.

\section{Desarrollo}

\section{MEtodoloGía}

La investigación centra su método de análisis en la hermenéutica y la técnica de la interpretación, partiendo del articulado de la ley, la cual será analizada desde la teoría del Derecho constitucional, con los reconocidos estudios de Alexy, Ferrajoli, Dworkin y Härbele, entre otros, complementándose con las publicaciones realizadas por el grupo de investigación sobre la temática, sumando los avances jurisprudenciales, para plasmar el argumento principal de la constitucionalización del derecho, que es como la Constitución permea ampliamente el ordenamiento jurídico.

\section{Resultados-Discusión}

\section{Hacia una concepción constitucional del Derecho Disciplinario}

La Corte Constitucional colombiana ha definido el Derecho disciplinario, referenciándola como esencial para el buen funcionamiento de las instituciones estatales. Una rama esencial al funcionamiento del Estado "enderezado a regular el comportamiento disciplinario de su personal, fijando los deberes y obligaciones de quienes lo integran, las faltas, las sanciones correspondientes y los procedimientos para aplicarlas" (Sentencia C-417, 1993, num. IV, inc. 3, párr. 2). Con ello, se pude decir, que el derecho disciplinario es una materia ateniente al derecho público, originada por mandato constitucional, y que a través de su formación se ha nutrido del Derecho administrativo y del Derecho penal, sin menospreciar otras ramas del derecho de las cuales también se ha valido para su consolidación. El derecho disciplinario "es guía para seguir en derecho comparado, lo cual ha sido obra de los importantes y significativos desarrollos que ha 
hecho la jurisprudencia de la Corte Constitucional a partir del ADN fijado en la Carta Política de 1991"(Gómez, 2019, p. 19).

La Constitución de 1991 establece la responsabilidad de los servidores públicos respecto a su extralimitación: "Los particulares sólo son responsables ante las autoridades por infringir la Constitución y las leyes. Los servidores públicos lo son por la misma causa y por omisión o extralimitación en el ejercicio de sus funciones" (CP, 1991, art. 6), y por tanto, son sujetos disciplinables si trasgreden los derechos constitucionales y las leyes del ordenamiento jurídico, y a su vez incurran en omisión o extralimitación en la práctica funcional. La prevalencia constitucional se encuentra acorde con la corriente teórica que se ha consolidado y posibilitado la transformación estatal para encontrarse más acorde con la orientación constitucional que surge de los principios y los derechos fundamentales, el Neoconstitucionalismo. "El neo-constitucionalismo pretende explicar el fenómeno de la Constitución como eje del Estado constitucional y democrático de Derecho, que se expresa por medio de los textos constitucionales incorporados recientemente por parte de los Estados contemporáneos" (Velasco y Llano, 2015, p. 61).

El Derecho disciplinario tiene entonces por obligación, el regular el comportamiento de los funcionarios públicos en el ejercicio de sus funciones, siendo su fin último, el garantizar el cumplimiento de los fines del Estado. "El Estado está en función de la garantía de los derechos fundamentales por parte de las instituciones públicas hacia los ciudadanos y personas, los deberes pasan a ser exclusivos de los fines del Estado y sus instituciones" (Llano, 2012, p. 48). Lo cual lo convierte en una herramienta de control, amparada en la facultad sancionadora, que por ejemplo opera a la trasgresión del contenido del artículo 209 de la Constitución:

La función administrativa está al servicio de los intereses generales [...] mediante la descentralización, la delegación y la desconcentración de funciones. Las autoridades administrativas deben coordinar sus actuaciones para el [...] cumplimiento de los fines del Estado. La administración pública, en todos sus órdenes, tendrá un control interno (CP, 1991, art. 209). 
Siendo un acápite de extremo valor para el correcto funcionamiento de un Estado constitucional y democrático de derecho, el ejercer una prevención que como mínimo garantice que el actuar de la función administrativa se conserve dentro de los linderos de lo correcto: "La cuestión de la única respuesta correcta depende esencialmente de sí el discurso práctico lleva a una única respuesta correcta para cada caso. Llevaría a ello si su aplicación garantizara siempre un consenso" (Alexy, 2002, p. 23). Por consiguiente, el Derecho disciplinario es la herramienta estatal garante del cumplimiento y aseguramiento de los fines, principios y valores, en el correcto desempeño de funciones por parte de los funcionarios públicos, con la extensión a los particulares que desempeñen funciones públicas: "La corrupción como práctica de los funcionarios impide el desarrollo de los fines esenciales del Estado, ya que no solo imposibilita establecer prosperidad para la ciudadanía, sino que también debilitan los derechos sociales" (Aponte, Llano y Sánchez, 2019, p. 105).

Cambiando el contexto de la década pasada en donde se concebía con la idea de que priorizar el principio de legalidad dentro de las codificaciones internas era suficiente para garantizar a los sujetos el respeto de los derechos; se le daba un carácter axiomático al principio, ya que protegía el sistema jurídico, le daba coherencia a las actuaciones de los servidores del Estado y a la de los individuos, delimitando el ámbito entre lo permitido y lo ilegal, determinando funciones para evitar las extralimitaciones del poder, es decir, un servidor público no solo está obligado dentro de sus actuaciones a regirse por el imperio de la ley por la mera existencia de una ley positiva, sino que además sus actuaciones deben estar justificadas por la razonabilidad y proporcionalidad.

[...] principio de legalidad no se circunscribe a la ley positiva [...] sino que se entronca al propio tiempo con la justicia, [...] encuentra el fundamento [...] del principio de interdicción de arbitrariedad [...] los funcionarios [...] tienen prohibido dictar órdenes o emitir actos administrativos contrarios a las leyes positivas, a la razón o a la justicia (Cassagne, 2009, p. 15). 
En la actualidad el legislador tuvo el ánimo de imprimir un reconocimiento al individuo y no a la ley, si bien están dada para preservar el sistema jurídico, la protección no es únicamente y exclusiva para el aparato estatal sino que el eje central de todas las leyes dentro del mismo sistema jurídico debe estar dispuesto para el pleno desarrollo de los derechos del individuo, y por ende, entiende que el Código General Disciplinario más que ser una ley expresa, la cual delimita las actuaciones tanto del servidor público como del individuo, esta se expide es para la ampliación de las garantías fundamentales de los sujetos. Dentro de las acepciones sobre dignidad humana se puede entender:

Si somos sujetos de dignidad, somos valor en sí, fin en sí, merecemos respeto [...] prioriza la necesidad de que el sujeto [...] sea reconocido en cuanto es un ser con derechos y libertades individuales que contribuyen a su realización humana (Amorocho, 2019, p. 219).

En la práctica el orden en que se codifican los principios no les da mayor o menor aplicación, pero se entiende que el legislador quiso preponderar la dignidad humana como muestra del garantismo que pretende la nueva Ley.

Pero la pretensión no es solamente garantizar unos principios y derechos, sino en lo posible ampliar a la Constitución en su totalidad, incluso incorporar los derechos que surgen desde los tratados y convenios internacionales, por medio del bloque de constitucionalidad. Desde esta perspectiva los principios constitucionales se convierten en orientadores en las distintas áreas del derecho, incluido lo respectivo al disciplinario: "Con el avance y transformaciones del derecho los principios, no se han limitado solamente a lo constitucional, sino que se ha expandido en las distintas áreas jurídicas" (Sánchez y Llano, 2019, p. 231).

La entrada de los derechos fundamentales y los principios constitucionales en las distintas áreas o ramas del derecho se ha conocido como constitucionalización, proceso al que no escapa el Derecho disciplinario al deber no solamente ceñirse a la producción legal sino también al complemento surgido desde el texto constitucional y 
su interpretación que es la jurisprudencia proveniente de las Altas Cortes:

La idea de constitucionalización del Derecho [...] está conectada con el efecto expansivo de las normas constitucionales cuyo contenido material y axiológico se irradia, con fuerza normativa, por todo el sistema jurídico [...] los principios y reglas de la Constitución empiezan a condicionar la validez (Barroso, 2013, p. 290).

El proceso de constitucionalización del derecho se soporta en concepciones teóricas que llevan a la transformación en un primer momento de la misma disciplina jurídica: "Desde la teoría y la filosofía del derecho, el neo-constitucionalismo se identifica como una nueva corriente del derecho constitucional anti-positivista, post-positivista, neopositivista [...] En el neo-constitucionalismo se otorga además a la Constitución un contenido material y sustancial" (Rusinque, 2017, pp. 468-469). En una segunda fase se transforma el campo jurídico:

La globalización al afectar a los Estados, también impacta a su principal instrumento, el derecho, situación que determina transformaciones en el campo jurídico . [...] así, como la difusión contemporánea del Neoconstitucionalismo [...] llegan inmediatamente a los sitios de recepción (Llano y Silva, 2018, p. 61).

El tercer momento ocurre con el modelo de Estado que se adecua a esos cambios e impulsa la consolidación de las reformas "jurisdicciones constitucionales en la definición y la conservación de los derechos fundamentales, y, más aún, en el paso progresivo del Estado legislativo de derecho al Estado constitucional de derecho, que restablece la Constitución en la cumbre de la jerarquía" (Martin, 2014, p. 12). Este modelo estatal se relaciona con el cuarto momento que es la relación del derecho con la sociedad acorde con una perspectiva más de la sociología jurídica, "el derecho ahora es visto y tratado como un fenómeno social: una institución, un sistema y un componente de la sociedad" (Treviño, 2020, p. 63). Relación que se refleja en los ciudadanos como titulares de derechos a los que las instituciones 
públicas se los deben garantizar y proteger, postulado que se lleva a la realidad y que caracteriza al Neo-constitucionalismo.

De este modo, la concepción constitucional del Derecho Disciplinario debe de ser entendida como un proceso de evolución con relación a las nuevas dinámicas sociales, económicas, políticas y estatales, que demandan un mejor funcionamiento de las instituciones estatales, y no solo debe de limitarse y regularse por el derecho penal y administrativo, sino que requiere un régimen disciplinario solido para los servidores públicos, pero basado en el respeto de los principios y derechos constitucionales como mecanismo de transparencia en todos los procesos de la administración.

Las legislaciones disciplinarias anteriores, daban prevalencia al principio de legalidad, teniendo en el imperio de la ley y su cumplimiento por parte de los ciudadanos el eje de la estructura jurídica; con las transformaciones constitucionales recientes se da una centralización a los derechos y la ley pasa un plano secundario, y para que las leyes mantengan el protagonismo que las ha caracterizado deben incluir los principios constitucionales en su articulado, por ende no solo se debe pensar en la protección de las instituciones, sino también el respeto de los principio y derechos establecidos para los sujetos disciplinables como una ampliación de las garantías fundamentales de los sujetos contenidas en la Constitución y los tratados internacionales, lo que permite determinar la incidencia constitucional en el régimen disciplinario.

\section{Principios constitucionales y teoría del derecho en el Código General Disciplinario}

Aunque desde el Neo-constitucionalismo y desde teorías del derecho como la argumentación jurídica que hacen parte de esta corriente, el Código Disciplinario, será concebido como una regla y esta es percibida como interior a los principios: "Las reglas son normas que exigen algo determinado [...] los principios son mandatos de optimización. Como tales, ellos exigen que algo sea realizado en la mayor medida posible, en función de las posibilidades jurídicas y fácticas del caso concreto" (Alexy, 2016, p. 25).Lo pertinente es como 
el articulado del Código incorpora distintos principios para darle un soporte que consolida este documento regulativo, para las acciones que realicen los funcionarios públicos y de los actores privados que se encuentren vinculados a las actividades estatales.

El primer principio que va aparecer en el Código General Disciplinario (Ley 1952, 2019) es la dignidad humana que se encuentra plasmado en el primer artículo de la parte general: "Quien intervenga en la actuación disciplinaria será tratado con el respeto debido a la dignidad humana" (art. 1). Para la teoría del derecho es un principio que ha sido determinante para la consolidación de los Estados de derecho contemporáneos: "En cuanto valor fundamental que, a la vez, es un principio constitucional, la dignidad humana funciona como justificación moral y como fundamento jurídico normativo de los derechos fundamentales" (Barroso, 2014, p. 115), convirtiéndose en el soporte de los distintos derechos fundamentales que poseen los ciudadanos: "La dignidad humana no sólo es en sí un derecho fundamental sino que constituye la base misma de los derechos fundamentales [...] todos los derechos fundamentales sirven a su respeto y a su desarrollo" (García, 2004, p. 81).

Posteriormente aparece el principio de legalidad, el cual desde lo teórico y lo constitucional tiene dos consideraciones importantes: la primera es que sirve para la limitación del poder, señalando expresamente las competencias y facultades del servidor público; y la segunda, señalar que es lo ilícito y lo lícito, y de allí se fundamenta en la imposición de una sanción. Sin embargo se debe señalar que este principio posee limitaciones por encontrarse en su implementación en el legislador que realiza sus funciones y acciones de acuerdo a su voluntad y no de la sociedad, precisamente, el alejarse de la realidad y de los intereses colectivos expone su limitación: "Se reconoce la capacidad limitada del derecho legislado para regular la realidad [...] bastante dudosa la capacidad del derecho para limitar de forma eficiente el poder punitivo del Estado por medio del principio de legalidad" (Domínguez, 2018, p. 70).

Para que la legalidad sea vinculante de forma adecuada en lo respectivo a la implementación del Código Disciplinario, debe com- 
plementarse con la legitimidad, principio que ha caracterizado las decisiones de las Altas Cortes, en especial la interpretación que realiza la Corte Constitucional en su jurisprudencia y que se encuentra soportada en el principio de legitimidad, el aspecto sustancial de los derechos y del modelo de Estado Constitucional; desde esta perspectiva se aclara la importancia de la legalidad:

Su posición central en la configuración del Estado de derecho como principio rector del ejercicio del poder y como principio rector del uso de las facultades tanto para legislar - definir lo permitido y lo prohibido- como para establecer las sanciones y las condiciones de su imposición (Sentencia C-710, 2001, num. V, inc. 1, párr. 4).

En el Código General Disciplinario el principio de legalidad aparece en el artículo 4, que tiene un contenido más explícito al indicar que se extiende y complementa la ley al momento de la adecuación de la conducta: "La preexistencia también se predica de las normas complementarias" (Ley 1952, 2019, art. 4, párr. 1), acudiendo de ser requerido al ordenamiento penal cuando el tipo no puede ajustarse dentro del régimen disciplinario. Cumpliendo con los principios de especialidad y subsidiariedad, "se someterá a los principios de especialidad y subsidiaridad” (Ley 1952, 2019, art. 4, párr. 2) determinando que si al momento de la adecuación típica se requiere la aplicación de otro precepto jurídico, este debe ser preexistente al comportamiento disciplinable.

Uno de los artículos donde aparece la teoría del derecho reciente, es el artículo 6 referente al principio de proporcionalidad que se encuentra en el Código General Disciplinario (Ley 1952, 2019) y donde aparece claramente su utilización: "La imposición de la sanción disciplinaria deberá responder a los principios de proporcionalidad y razonabilidad" (art. 6, párr. 1). Precisamente, el teórico de la argumentación jurídica, Alexy (2007), ha explicado de forma adecuada el principio de proporcionalidad: "Interpretar los derechos constitucionales a la luz del principio de proporcionalidad supone [...] exigencias de optimización; esto es como principios y no como simples reglas" (p. 61). La colisión entre principios por un determinado 
caso concreto que distingue el derecho constitucional contemporáneo se resuelve por medio de la ponderación como acción que hace parte de la proporcionalidad; "el propósito de la ponderación debe ser el de resolver presuntos conflictos entre principios y ayudar a todos los órganos del Estado en su tarea de optimizar apropiadamente los derechos y otros principios contrapuestos" (Stone y Matthews, 2013, p. 50).

La ponderación se ha convertido en la metodología por excelencia para la garantía de los derechos fundamentales por parte del Estado hacia los ciudadanos, debido a que pondera principios o derechos de acuerdo a un determinado caso. En la aplicación de la ponderación los jueces constitucionales han sido determinantes: "La ponderación se ha convertido en una operación metodológica esencial, particularmente para la protección de los derechos fundamentales, salvaguardados por la última ola de Constituciones de Europa continental y Latinoamérica que tienen la estructura de principios" (Bernal, 2015, p. 105). Con respecto a la razonabilidad la Corte Constitucional la ha definido como:

[...] adscripción, prima facie, de (a) [...] - La pretensión del titular del derecho (nivel de satisfacción pretendido) [...], (b) - [...] La política pública, programa o medida acusada (nivel de satisfacción provisto) [...] o las otras alternativas razonables de satisfacción al contenido prestacional del derecho (Sentencia T-461, 2018, num. II, inc. 5, lit. ii, it. 105, párr. 2).

La Corte Constitucional en su jurisprudencia ha señalado que hay una relación complementaria entre los principios de proporcionalidad y de razonabilidad, toda vez que la aplicación del principio de proporcionalidad se hace satisfactoriamente cuando hay dos o más principios que se encuentran colisionando, y que por lo tanto puede generar por la elección de uno, el perjuicio de uno de ellos, por ende, en el caso de la calificación de la falta y su graduación, debe haber una ponderación de proporcionalidad y racionalidad; que aquella calificación este contenida dentro de los límites de la ley, y no vaya a generar un daño desproporcionado al sujeto en otros derechos: 
El concepto proporcionalidad sirve como [...] apoyo de ponderación [...] cuando dos principios entran en colisión, porque la aplicación de uno implica la reducción [...] de otro, corresponde [...] determinar si esa reducción es proporcionada, a la luz [...] del principio afectado (Sentencia C-022, 1996, inc. 6.3.3, párr. 8.)

El siguiente artículo del Código Disciplinario expone uno de los principios esenciales y que además ha suscitado críticas desde la teoría del derecho, el de igualdad, que es considerado un principio liberal: "Uno de los principios fundamentales del liberalismo: la igualdad [...] el Estado debe actuar de manera que haga las vidas de aquellos a quienes gobierna mejores vidas y debe mostrar igual consideración por la vida de cada uno" (Bonilla y Jaramillo, 2004, pp. 56-57). Incluso en las decisiones políticas que afectan las distintas instituciones estatales se debe recurrir al principio de igualdad: "En una democracia genuina, el pueblo gobierna no en forma estadística sino en forma comunitaria [...] un agente comunitario, el pueblo, en el marco del cual los ciudadanos individuales figuren como miembros iguales" (Dworkin, 2010, pp. 130-131).

Desde la Corte Constitucional el principio de igualdad ha sido concebido de forma amplia y adecuado a las decisiones jurisprudenciales: "Igualdad es relacional y siempre presupone una comparación entre personas o grupo de personas [...] abstracto todos somos personas iguales y en concreto somos individuos diferentes, es preciso identificar un parámetro para valorar semejanzas relevantes y descartar diferencias irrelevantes" (Sentencia C-138, 2019). La igualdad se percibe en relación con el discurso racional teniendo como responsable al juez que lo interpreta desde las reglas del discurso para que la objetividad sea predominante: "Será válido hablar de la máxima de la igualdad como aquella que fundamenta el trato desigual en el discurso racional [...] dicho trato diferenciador será constitucional si y solo si el juez motiva su fallo en argumentos racionales" (Hernández y Jiménez, 2017, p. 73)

El Código General Disciplinario (Ley 1952, 2019) retoma la generalidad del principio de igualdad para evitar discriminación en sus distintos procedimientos: "Las autoridades disciplinarias deberán 
hacer efectiva la igualdad de los intervinientes en el desarrollo de la actuación procesal y proteger, especialmente, a aquellas personas que por su condición económica, física y mental, se encuentren en circunstancias de debilidad manifiesta" (art. 7). Precisamente el principio de igualdad es esencial en la configuración del Estado constitucional y democrático de derecho: "La igualdad liberal trata de organizar en un esquema teórico coherente exigencias de igualdad, libertad y eficiencia, manteniendo la congruencia con los presupuestos básicos de un Estado constitucional democrático" (Santos, 2017, p. 25).

El Derecho disciplinario se soporta en el principio de ilicitud sustancial, el cual pretende una mayor responsabilidad de los actos del funcionario en las instituciones públicas; que en sus acciones y decisiones no se impacte negativamente la realización de los deberes que se encuentra enmarcados por los reglamentos, las leyes y la Constitución. El desconocimiento y transgresión de estos documentos jurídicos llevaría a una afectación, incluso de la finalidad del Estado constitucional y democrático de derecho: "Ilicitud sustancial aparece como un referente para la aplicación de la sanción, si existe la afectación al deber funcional sin justificación alguna [...] los funcionarios públicos son responsables ante las autoridades por infringir la Constitución y las leyes" (Ramírez, 2014, p. 10).

Este principio en el momento de proclamación de la ley va a tener una definición y función específica en lo concerniente a los funcionarios públicos que cometen conductas o acciones, las cuales están en contra de su función y responsabilidad: "La conducta del sujeto disciplinable será ilícita cuando afecte sustancialmente el deber funcional sin justificación alguna. Habrá afectación sustancial del deber cuando se contraríen los principios de la función pública” (Ley 1952, 2019, art. 9).

Sin embargo, pese a que el principio de ilicitud parece reducirse por su acción específica, este no pierde su horizonte, debido a que la misma ley en su Libro I, Parte General, Título I, se titula "Principios y normas rectoras de la ley disciplinaria" (Ley 1952, 2019), encontrándose acorde con los postulados de la teoría del derecho que considera los principios como esenciales para las regulaciones contemporáneas: 
"Ya que los principios - en virtud de su (supuesta) superioridad axiológica con respecto de las reglas - orientan la interpretación de las (disposiciones que expresan) reglas. Las disposiciones que expresan reglas son tendencialmente interpretadas [...] conforme a los principios" (Guastini, 2014, p. 113).

Entre las teorías del derecho que se nutren de la consolidación de los principios como postulados que tienen una amplia regulación y pueden resolver distintos problemas jurídicos se encuentra el Neoconstitucionalismo: "vocablo pensado para denominar una doctrina ius-filosófica aparentemente anti-positivista, que se dirige a una particular reconstrucción del derecho del estado constitucional y de su carta fundamental, que promueve la interpretación moral [...] al nivel de los principios constitucionales" (Pozzolo, 2013, pp. 36-37). De este movimiento hacen parte diferentes enfoques como la argumentación jurídica: "La teoría de la argumentación jurídica ha conocido en los últimos años un extraordinario desarrollo [...] teóricos y filósofos del derecho [...] el esfuerzo por construir modelos de racionalidad que sirvan como guía para la toma de decisiones jurídicas" (Alexy, 2012, p. 15). O el garantismo, donde los derechos fundamentales deben garantizarse por parte de las instituciones estatales a los ciudadanos:

Las funciones de garantía, no solo las jurisdiccionales o secundarias sino también las administrativas o primarias como la educación, la asistencia sanitaria y la previsión social, están en cambio legitimadas por su sujeción a la ley y, en particular a los derechos fundamentales (Ferrajoli, 2018, p. 51).

Entre los teóricos del derecho que en un primer momento expondrá la importancia de los principios y la diferencia con las normas para resolver los problemas jurídicos se encuentra Dworkin: "Los principios tienen una dimensión que falta en las normas: la dimensión del peso o importancia. Cuando los principios se interfieren [...] quien debe resolver el conflicto tiene que tener en cuenta el peso relativo de cada uno" (Dworkin, 2012, p. 77). Como se ha argumentado, este postulado del peso para los principios que propone Dworkin es recogido por Alexy (2013a) al consolidar su teoría con la proporcionalidad, la 
ponderación y la fórmula del peso, y además logra ampliar la relación de los principios con los derechos fundamentales: "La concepción de los derechos como principios de ninguna manera está en oposición a la idea de los derechos como escudos. Tal concepción busca por el contrario concretar en mayor medida posible la idea de los derechos como escudos" (Alexy, 2013a, p. 444).

Precisamente, los principios que se han presentado en el Código General Disciplinario no se limitan a la dignidad humana, legalidad, cosa juzgada o ilicitud sustancial, sino que se amplía a otros que se expondrán, como el principio de culpabilidad adicionándose que la imposición de sanción solo puede versar sobre "conductas realizadas con culpabilidad. Las conductas solo son sancionables a título de dolo o culpa" (Ley 1952, 2019, art. 10). Ante este principio la Corte Constitucional ha señalado que es un derecho de los ciudadanos el que las conductas a investigar y sancionar sean por el principio de culpabilidad, y no basándose en la mera producción del resultado, sin que haya medido el dolo o la culpa, que es la intención de cometer la conducta dañosa con plena conciencia o por la omisión de una conducta que debía de preverse:

En principio la Constitución colombiana impone la garantía para los ciudadanos la aplicación de los principios de culpabilidad y de imputación. De aquí se ha extraído el principio según el cual la construcción prohíbe prima facie sanciones basadas en responsabilidad objetiva, es decir por el mero hecho del acaecimiento material o naturalístico de la conducta jurídicamente reprochada y prohibida (Sentencia C-699, 2015, num. III, inc. 1.4, párr. 2).

El que la Ley 1952 (CGD, 2019) incorporará principios y derechos fundamentales en su articulado muestra un proceso donde las teorías y concepciones del derecho tienen prevalencia; ya no se reduce simplemente a una normatividad sino que esta relaciona el Derecho constitucional contemporáneo con el fenómeno de constitucionalización y la incorporación del Derecho Internacional de los Derechos Humanos, por medio del bloque de constitucionalidad, eso muestra una diferencia sustancial con las anteriores leyes sobre lo disciplinario al interior del Estado. 


\section{Los principios procesales en el Código General Disciplinario}

En donde se encuentran varios principios constitucionales vinculados al Código Disciplinario, es en el artículo 11 (CGD, 2019), sobre Fines del Proceso Disciplinario, donde aparece uno de los principios que ha sido de amplias deliberaciones en la ciencia jurídica, especialmente en lo respectivo a la teoría y la filosofía del derecho, la justicia: "Las finalidades del proceso son la prevalencia de la justicia" (Ley 1952, 2019, art. 11), entendiendo desde las teorías más recientes a la justicia como un principio esencial cuando se trate de la aplicación del derecho: "Si existen nociones de justicia fundamentales racionalmente, puede decirse entonces que quien, sobre la base de una fundamentación racional, considera que una acción es injusta, está en capacidad de reconocerlo" (Alexy, 2013b, p. 82). Precisamente, la injusticia se reproduce al no reconocer, garantizar y proteger los derechos fundamentales: "Intolerable injusticia representada por la inefectividad y la ausencia de garantías de los derechos fundamentales en gran parte del planeta y sobre las razones morales o incluso solo, en los plazos largos, de simple conveniencia de una efectiva garantía" (Ferrajoli, 2016, p. 20).

En el mismo artículo 11 (Ley 1952, 2019) se señala la efectividad que desde la sociología jurídica se ha estudiado para observar la coincidencia entre la norma y la conducta a quienes va dirigida: "Es efectiva, si una observación sociológica, es decir una observación de hechos, comprueba que el individuo al que el derecho se dirige produce una conducta a la que puede atribuirse el mismo sentido" (Correas, 2009, p. 180). Lo que se pretende es que sean cumplidas las leyes, la jurisprudencia y la Constitución en lo relacionado al Código disciplinario y los procesos que se inician cuando los funcionarios realizan acciones contrarias a lo establecido en el campo jurídico, pero también prevenir para que dichas conductas ilícitas no sean llevadas a cabo. Lo interesante es que en ese mismo artículo 11 (CGD, 2019) se encuentre plasmado el principio de verdad material, que se encuentra acorde constitucionalmente con las acciones que se realizan para determinar el cumplimiento o la vulneración de las funciones de los servidores públicos: "Aproximación a la verdad es un fin, un 
principio y un derecho constitucional que se impone a las autoridades y a los particulares [...] tendiente a materializar un orden justo que se soporte en decisiones que consulten la realidad" (Sentencia SU-768, 2014, párr. 1).

Inclusive se puede deducir que la Ley 1952 (CGD, 2019) tiene un soporte de teoría del derecho al exponer "el cumplimiento de los derechos y garantías debido a las personas que en él intervienen" (art. 11). Se estarían plasmando el postulado teórico de Ferrajoli que es el garantismo y que se soporta en el reconocimiento y aplicación de los derechos fundamentales: "Los derechos de libertad, sin cuya garantía quedan vacíos los derechos políticos, y de los derechos sociales, cuya satisfacción es a su vez una condición necesaria para la efectividad de todos los demás derechos" (Ferrajoli, 2009, p. 125). Este artículo del Código Disciplinario no solamente expone los principios generales que han caracterizado el derecho y la teoría que se encuentra detrás de la ley sino que también incorpora el derecho sustantivo que tiene relación con la estructura que caracteriza los derechos fundamentales, "la efectividad del derecho sustantivo" (Ley 1952, 2019, art. 11), con la pretensión de que las prácticas ilegales y que están aportando al detrimento estatal sean disminuidas y lograr que el funcionamiento sea lo mejor posible:

Mecanismo para hacer efectivo este sistema de control de los servidores públicos, [...] con la finalidad de asegurar el eficiente funcionamiento estatal [...] justifica la existencia de reglas para ejercer la actividad pública que responda a principios de igualdad, moralidad, eficacia (Gómez, 2009, p. 14).

En el artículo 12 (Ley 1952, 2019) aparece uno de los principios esenciales para determinar la culpabilidad o inocencia de un funcionario investigado, que es el debido proceso; para este caso se limita a que este procedimiento sea realizado por las autoridades competentes y las respectivas condiciones para que se logre un juzgamiento que pretenda la objetividad: "El sujeto disciplinable deberá ser investigado y juzgado por funcionario competente y con observancia formal y material de las normas que determinen la ritualidad del proceso" (Ley 
1952, 2019, art. 12). La incorporación de este principio a la ley logra garantizar que los procedimientos que se adelanten en las respectivas investigaciones gocen de cierta imparcialidad para el sujeto que se encuentra en el proceso: "Debido proceso es un derecho fundamental contentivo de principios y garantías que son indispensables de observar en diversos procedimientos para que se obtenga una solución sustancialmente justa, requerida siempre dentro del marco del estado [...] democrático y de derecho" (Pérez, 2017, p. 1075).

Entre los derechos procesales que se consideran importantes para el desenvolvimiento adecuado de disciplina jurídica se encuentra la presunción de inocencia, que ha sido desarrollado por el derecho internacional por medio de los convenios y tratados; es el caso del Estatuto de Roma que lo tiene incorporado en el artículo 66: “1. [...] toda persona es inocente mientras no se pruebe su culpabilidad ante la Corte de conformidad con el derecho aplicable. 2. Incumbirá al Fiscal probar la culpabilidad del acusado. 3. [...] sentencia condenatoria, la Corte deberá estar convencida" (Oficina del Alto Comisionado de las Naciones Unidas para los Derechos Humanos, OHCHR, 2020, art. 66) y la Convención Americana de los Derechos Humanos en su artículo sobre las Garantías Judiciales: "Toda persona inculpada de delito tiene derecho a que se presuma su inocencia mientras no se establezca legalmente su culpabilidad. Durante el proceso, toda persona tiene derecho, en plena igualdad" (Organización de Estados Americanos-OEA, 1969, art. 8, num. 2). Precisamente, el Código Disciplinario recoge este principio y derecho de la presunción de inocencia en su artículo 14: "El sujeto disciplinable se presume inocente y debe ser tratado como tal mientras no se declare su responsabilidad en falle ejecutorio" (Ley 1952, 2019), esto determina cierta garantía en el proceso que se adelante a los involucrados en la investigación realizada por parte de las instituciones responsables.

Este principio y derecho de presunción de inocencia se encuentra relacionado con el derecho a la defensa que proviene de la familia jurídica anglosajona, siendo reconocido y fortalecido con los diversos pronunciamientos de las altas cortes colombianas: "derecho de defensa [...] supone la posibilidad de emplear todos los medios legítimos y 
adecuados para ser oído y pretender una decisión favorable, [...] posibilidad de que toda persona pueda emplear todas las herramientas y mecanismos adecuados para defenderse" (Sentencia C-163, 2019, num. VI, lit. ii, inc. 12). En la Ley 1952 (CGD, 2019) aparece en el artículo 15, el derecho de defensa en concordancia con los avances jurisprudenciales: "El investigado tiene derecho a la defensa material y a la designación de un abogado [...] solicita la designación de un defensor así deberá procederse. Cuando se juzgue como persona ausente [...] representado a través de apoderado judicial" (2019, art. 15).

El principio universal de cosa juzgada pueda aplicarse desde el régimen disciplinario sin concurrir a otra normatividad, indicando que el sujeto objeto de un fallo ejecutoriado o decisión equiparable al orden disciplinario, siempre y cuando este proferido por una autoridad competente, hará tránsito a cosa juzgada, "por lo cual no habrá lugar a un nuevo proceso por el mismo hecho". (Ley 1952, 2019, art. 16). Esto lleva a una deliberación sobre la cosa juzgada debido a que desde una perspectiva administrativa sería el final del proceso, sin embargo al procesado que vulnere derechos fundamentales en su acción, este principio se limitaría ya desde una mirada constitucional: "La cosa juzgada no como valor absoluto sino como elemento que infunde seguridad a la realización de la justicia [...] las decisiones de los jueces [...] podrán ser sometidas a revisión cuando quiera que vulnere derechos fundamentales" (Quinche, 2006, p. 212).

Desde esta orientación constitucional, solo puede imponérsele sanción por comportamientos disciplinables cuando el servidor público incurre en alguna causal al sancionarse por el mismo Código General Disciplinario, o a falta de comportamientos tipificados en este, algún acto ilícito que se encuentre por ejemplo en la legislación penal, pero en todo caso, debe haber una preexistencia de las normas al momento de la realización del acto ilícito; para el caso de los delitos que se desprende de la corrupción es determinante esa claridad procedimental, sancionatoria y penal, debido a que los cambios en las legislaciones y el derecho internacional son constantes con las miras del control de esta actividad ilegal, en las más recientes proclamaciones legales 
aparecen delitos que no se encontraban plasmados en las anteriores leyes: "Se introdujeron por primera vez en nuestra legislación penal tipos penales de corrupción en el ámbito privado. En este sentido se integraron en el código penal los artículos 250A (Corrupción privada) y 250B (Administración desleal)" (Serrano, 2019, p. 273).

En el artículo 21 del Código que se denomina cláusula de exclusión se convierte en un referente para la protección de los derechos fundamentales en pleno proceso investigativo con un cuestionamiento especifico en lo correspondiente al material probatorio: "Toda prueba obtenida con violación de los derechos y garantías fundamentales será nula de pleno derecho, por lo que deberá excluirse de la actuación procesal" (Ley 1952, 2019, art. 21), este postulado expone la supremacía de los derechos fundamentales sobre los procedimientos técnicos y legales, en concordancia con las transformaciones estatales y jurídicas recientes:

[...], principio de supremacía de la Constitución implica, entonces, que toda norma y todo acto jurídico del Estado y de los particulares debe ser conforme a la Constitución [...] normas o actos [...] contraría la Constitución, estará llamado a inaplicarse (Bernal, 2018, p. 45).

En el artículo final del Código General Disciplinario se plasma no solamente la supremacía de la Constitución sino también la incidencia de los tratados y convenios internacionales tanto en el ordenamiento jurídico como en las decisiones que se tomen por parte de las instituciones y funcionarios públicos que realicen los distintos procesos investigativos y sancionatorios:

[...] prevalecerán los principios rectores contenidos en la Constitución [...] además de los tratados y convenios internacionales ratificados por Colombia”, aquí es de destacar la vinculación de las Declaraciones $\mathrm{y}$ documentos internacionales que se han vinculado por medio del bloque de constitucionalidad al ordenamiento jurídico nacional: "la jurisprudencia de la Corte Constitucional ha establecido que las normas de derecho internacional de los derechos humanos [...] integran al ordenamiento colombiano con rango de disposiciones constitucionales [...] con eficacia directa [...] en la solución de casos concretos" (Osuna, 2017, p. 363). 
En algunos casos son los mismos tribunales internacionales que intervienen en decisiones administrativas y disciplinarias en el país cuando se vulneran derechos o no se ha cumplido con los procedimientos y las investigaciones pertinentes para sancionar a los responsables; uno de los casos destacados fue lo sucedido al político Gustavo Petro cuando era alcalde de Bogotá, que ante una decisión administrativa y disciplinaria para salir del cargo, la Comisión Interamericana de Derechos Humanos (CIDH, Resolución 5, 2014) le otorgo medidas provisionales, manteniéndose como alcalde hasta el final de su periodo: "La comisión solicita al Gobierno de Colombia que suspenda inmediatamente los efectos de la decisión del 9 de diciembre 2013 [...] ratificada por la Procuraduría General de la Nación [...] garantizar [...] los derechos políticos del señor [...] Petro" (p. 1, inc. 3).

Pese a que prácticamente el Código General Disciplinario se constitucionalizo desde sus inicios y principalmente en el Libro I, Parte General, Título I, "Principios y Normas Rectoras de la Ley Disciplinaria" (Ley 1952, 2019), considerado como un avance determinante para el buen desenvolvimiento de la función pública. Las acciones ilegales por algunos de los distintos funcionarios es una constante, una de las más conocidas públicamente es lo referido a la corrupción donde el detrimento patrimonial estatal se ha acentuado con el tiempo; esto lleva a cuestionar la eficacia del Código, debido a que los sancionados por acciones de corrupción o relacionadas con ellas es una minoría, enviando un mensaje de impunidad a quienes realizan estas prácticas, las cuales están en contra de lo que debe caracterizar el funcionario público; por eso este tipo de actividades no logran limitarse y por el contrario se está en aumento afectando las arcas estatales que en últimas perjudican a los ciudadanos donde no llegan los recursos destinados a las inversiones sociales.

Ante esta situación, los ajustes que se realicen para que la impunidad disminuya en las acciones ilegales de los funcionarios públicos debe provenir no solamente desde perspectiva sancionatoria sino que deben realizarse análisis socio-jurídicos para que las correcciones institucionales sean de forma holística, claro, combinado con los 
respectivos desarrollos legales y jurisprudenciales para evitar que los investigados no se le vulneren los derechos y se conviertan en demandas que afectarían precisamente los recursos que se buscan proteger.

Se puede inferir entonces, que la modificación y reestructuración de los principios procesales del Código General Disciplinario va mas allá del resguardo de los derechos y garantías que le asisten al sujeto disciplinable, sino que en procura del resguardo de las instituciones estatales, establece los principios procesales fundantes del régimen, donde se vislumbran los fines del proceso disciplinario como una búsqueda de justicia y eficacia de la norma jurídica, se establece principios como el de la verdad material, el debido proceso, la presunción de inocencia, la cosa juzgada, preexistencia de la conducta punible, la cláusula de exclusión, y la prevalecerán los principios rectores contenidos en la Constitución y los tratados y convenios internacionales ratificados por Colombia; considerando esta estructuración como un progreso preciso para el desenvolvimiento correcto de la función pública, donde tanto el sujeto como la administración contemplen un desarrollo transparente en un proceso disciplinario, es decir que tanto el Estado como el sujeto tengan plenas garantías dentro de la actuación disciplinaria con el fin de obtener una verdadera justicia.

\section{Conclusiones}

La promulgación de la Ley 1952 en el 2019, impulsa transformaciones sustanciales y procesales de magnitud e impacto para el derecho disciplinario en el país y que se encuentra relacionados con los fines que caracteriza los modelos de Estado social de derecho y Estado constitucional y democrático de derecho que se han pretendido implementar desde la Constitución de 1991; precisamente, para contribuir a esta realización constitucional en la realidad social se ha vuelto esencial el control de unas de las acciones que perjudican la garantía de derechos sociales fundamentales, las prácticas de corrupción por parte de funcionarios y contratistas con el Estado. El paso a la constitucionalización del derecho disciplinario expone un 
proceso transformación de las instituciones estatales que pretende frenar las actuaciones ilegales de los funcionarios públicos y aquellos particulares que prestan un servicio estatal, aquí el régimen disciplinario adquiere un inusitado protagonismo, en concordancia con la prevalencia de los principios y derechos constitucionales.

Estas transformaciones acordes al Estado constitucional y democrático de derecho no se limita solamente una sanción disciplinaria en contra de un sujeto disciplinable, sino que se debe garantizar a aquellos que sean llevado a los procesos disciplinarios sus garantías y derechos constitucionales con el fin de ejercer un mecanismo trasparente donde principios constitucionales e internacionales como la dignidad humana y el debido proceso permeen cada actuación; lo que comparando con las legislaciones precedentes es un gran avance, toda vez que anteriormente prevalecía el imperio de la ley sobre los principios y derechos de los individuos disciplinables. El derecho disciplinario tiene por obligación orientar la actuación de los funcionarios públicos y los particulares que desarrollan funciones públicas por medio del respeto a la Constitución y de este modo garantizar la observancia y acatamiento de los fines del Estado, este régimen no solo se centra en la protección de las instituciones a través de la sanción, sino que prevé un enfoque de prevención que intenta demarcar las actuaciones administrativas nocivas para el Estado y que el servidor se abstenga de cometerlas, y por otro lado desde un enfoque correctivo, cuando la conducta del funcionario no se adecue a garantizar el aseguramiento de los principios y valores establecidos en la Constitución.

La modificación y restructuración tanto de los derechos como de los principios procesales del Código General Disciplinario posibilita la protección del sujeto, sin perder la pretensión del equilibrio entre los derechos que le asisten al procesado y las acciones que llevan a un detrimento económico de las entidades públicas por actuaciones ilegales de los servidores y prestadores públicos. El proceso disciplinario es una proporción entre justicia y eficacia de la norma jurídica y la prevalencia de los derechos y principios constitucionales a lo que se suma el bloque de constitucionalidad. Los principios constitucionales 
en el nuevo Código General Disciplinario reorganizan, adicionan y complementan el contenido del régimen disciplinario, por medio de la supremacía de la Constitución y la inclusión de tratados y convenios internacionales, esto con la pretensión de que las decisiones que se tomen por parte de las instituciones y funcionarios que realizan los distintos procesos investigativos y sancionatorios, estén acordes con las garantías constitucionales y convencionales.

Se debe aclarar que estas transformaciones son iniciales, apenas se encuentra en las primeras fases de implementación para lograr un funcionario público que se encuentre en sus actividades soportado en la Constitución y los tratados internacionales donde la garantía de derechos sea lo prioritario, las decisiones que se realizan desde este nuevo Código serán el precedente para que las conductas contrarias a las leyes, la jurisprudencia y los derechos disminuyen ostensiblemente y posibilitar el cumplimiento de los derechos fundamentales hacia los ciudadanos colombianos. El papel de la academia es esencial por convertirse en los innovadores en distinta áreas formativas, entre ellas las relacionadas con el campo jurídico, se debe formar abogados expertos en esta materia, ya que se abrió un nuevo campo de ejercicio de la profesión en lo concerniente a las reformas y ajustes realizados al nuevo Código Disciplinario, por ejemplo la normatividad anterior no traía consigo la exigencia a una defensa técnica, la nueva lo tiene claramente incorporado, por ende se hace recomendable que el abogado defensor cuente con las cualificaciones pertinentes para ejercer esta práctica especializada; exigencia necesaria para quien ejerce la potestad disciplinaria.

Precisamente, la consolidación de las pretensiones de un funcionario público acorde a los desafíos constitucionales necesita de la coordinación entre las distintas instituciones estatales, la academia socio-jurídica que por medio de sus centros y grupos de investigación pueden determinar los avances y deficiencias en las conductas de funcionarios y la responsabilidad estatal, la jurisprudencia constitucional nacional e internacional para los casos complejos y la sociedad en general que se vea afectada por las relaciones con las instituciones y sus funcionarios en la práctica cotidiana. 


\section{REFERENCIAS}

Alexy, R. (2016). Principios formales. Algunas respuestas a los críticos. En, J. Portocarrero (Ed.), Ponderación y discrecionalidad (pp. 23-57). Bogotá, D.C.: Universidad Externado.

Alexy, R. (2013a). Trece respuestas. En, G. Pavlakos (Ed.), Derecho, Derechos y Discurso. La filosofía juridica de Robert Alexy (pp. 431-471). Bogotá, D.C.: Universidad Externado.

Alexy, R. (2013b). Una respuesta a Joseph Raz. En, G. Pavlakos (Ed.), Derecho, Derechos y Discurso. La filosofía juridica de Robert Alexy (pp. 61-85). Bogotá, D.C.: Universidad Externado.

Alexy, R. (2012). Teoría de la argumentación jurídica. Madrid: Centro de Estudios Políticos y Constitucionales.

Alexy, R. (2007). Teoría del discurso y derechos constitucionales. México, D.F.: Fontamara.

Alexy, R. (2002). Derecho y razón práctica. México, D.F.: Fontamara. Amorocho, E. (2019). De la exclusión social al reconocimiento de la dignidad en los contextos educativos. Revista de Estudios Socioeducativos ReSed, (7), 216-226. http://dx.doi. org/10.25267/Rev_estud_socioeducativos.2019.i7.15

Aponte, M., Llano, J. y Sánchez, G. (2019). Corrupción, control estatal y acuerdo de paz en Colombia. En, J, Llano y N. Velasco (Ed.), Pos-acuerdo y territorio en las comunidades indigenas, afro y campesinas en el Norte del Cauca (pp. 101-136). Bogotá, D.C.: Ibáñez/Universidad Libre.

Barroso, L. (2014). La dignidad de la persona humana en el derecho constitucional contemporáneo. La construcción de un concepto jurídico a la luz de la jurisprudencia mundial. Bogotá, D.C.: Universidad Externado.

Barroso, L. (2013). El Neoconstitucionalismo y la Constitucionalización del Derecho (El triunfo tardío del derecho constitucional en Brasil). En, C, Hernández y S, Ortega (Eds), Neoconstitucionalismo y equilibrio reflexivo (pp. 271-335). Bogotá, D.C.: Universidad Libre. 
Bernal, C. (2018). Derechos, cambio constitucional y teoría jurídica. Bogotá, D.C.: Universidad Externado.

Bernal, C. (2015). El precedente y la ponderación. En: C, Bernal Pulido y T, Bustamante (Eds.) Fundamentos filosóficos del precedente judicial (pp. 105-124). Bogotá, D.C.: Universidad Externado.

Bonilla, D. y Jaramillo, I. (2004). El igualitarismo liberal de Dworkin. En, R. Dworkin (Ed.), La comunidad liberal. Bogotá, D.C.: Universidad de los Andes y Siglo del Hombre.

Cassagne, J. (2009). El principio de legalidad y el control judicial de la discrecionalidad administrativa. Madrid: Marcial Pons.

CIDH. (18 de marzo de 2014). Gustavo Francisco Petro Urrego respecto de la República de Colombia. [Resolución 5]. Medida Cautelar: No. 374-13. Recuperado de https://www.oas.org/ es/cidh/decisiones/pdf/2014/MC374-13-ES.pdf

Correas, O. (2009). Introducción a la Sociología Jurídica. México, D.F.: Fontamara.

Domínguez, J. (2018). La frágil condición sistémica del derecho y sus efectos en los principios de legalidad y Nulla Poena Sine Lege. En, C. Deik (Ed.). La crisis del Estado de derecho (pp. 37-74). Bogotá, D.C.: Universidad Externado.

Dworkin, R. (2012). Los derechos en serio. Barcelona: Ariel.

Dworkin, R. (2010). Igualdad, democracia y Constitución: nosotros, el pueblo, en los tribunales. En, M, Carbonell y L, García (Ed.), El canon Neoconstitucional (pp. 117-152). Bogotá, D.C.: Universidad Externado.

Ferrajoli, L. (2018). Constitucionalismo más allá del Estado. Madrid: Trotta.

Ferrajoli, L. (2016). Derechos fundamentales, democracia fundamental y garantismo. Bogotá, D.C.: Universidad Libre.

Ferrajoli, L. (2009). Garantismo. Una discusión sobre derecho y democracia. Madrid: Trotta. 
García, R. (2004). Derechos humanos e injusticias cotidianas. Bogotá, D.C.: Universidad Externado.

Gómez, C. (2019). La lucha por los derechos en el derecho disciplinario. A propósito de la anunciada reforma. Bogotá, D.C.: Universidad Externado.

Gómez, C. (2009). Dogmática del Derecho Disciplinario. Bogotá, D.C.: Universidad Externado.

Guastini, R. (2014). Otras distinciones. Bogotá, D.C.: Universidad Externado.

Hernández, C. y Jiménez, C. (2017). Robert Alexy y la ponderación en la Corte Constitucional. Bogotá, D.C.: Universidad Libre.

Häberle, P. (2018). El Estado constitucional. México, D.F.: UNAM.

Llano, J. (2012). Estado constitucional: La protección de derechos y dificultades en su concreción. Criterio Libre Jurídico, 9(1), 45-58. https://doi.org/10.18041/1794-7200/criteriojuridico.1\%20Enero-Ju.741

Llano, J. y Silva, G. (2018). Globalización del derecho constitucional y constitucionalismo crítico en América Latina. Revista Utopía y Praxis Latinoamericana, 23(Extra 2), 59-73. http://doi.org/10.5281/zenodo.1799330

Martin, A. (2014). Introducción. En, A. Martin (Dir.), Justicia Constitucional, derechos humanos y democracia en América Latina (pp. 11-30). Bogotá, D.C.: Universidad Externado.

OEA. Departamento de Derecho Internacional. (1969). Convención Americana Sobre Derechos Humanos Suscrita en la Conferencia Especializada Interamericana de Derechos Humanos. [Online]. https://www.oas.org/dil/esp/tratados_b 32_convencion_americana_sobre_derechos_humanos.htm

ONU. OHCHR. (2020). Estatuto de Roma de la Corte Penal Internacional. [Online]. https://www.ohchr.org/SP/ProfessionaIInterest/Pages/InternationalCriminalCourt.aspx

Osuna, N. (2017). Derechos y libertades constitucionales. En, M, Correa,. N, Ousma y G. Ramírez (Eds.), Lecciones de Derecho Constitucional. Bogotá, D.C.: Universidad Externado. 
Pérez, J. (septiembre, 2017). Las formas propias del juicio como garantía del debido proceso y su relación con el principio de prevalencia sustancial. Conferencia presentada al $X X X$ VIII Congreso Colombiano de Derecho Procesal. ICDP, Cartagena, Colombia. Disponible en http://www.icdp.org.co/ anterior/congreso/congreso2017/index.html

Pozzolo, S. (2013). Metacrítica del neoconstitucionalismo. Una respuesta a los críticos de Neoconstitucionalismo y positivismo jurídico. En, C, Hernández y S, Ortega (Dirs), Neoconstitucionalismo y equilibrio reflexivo (pp. 27-59). Bogotá, D.C.: Universidad Libre.

Quinche, M. (2006). Seguridad jurídica y volatilidad constitucional en un Estado complejo. En, R. Sanín (Coord.), Justicia constitucional. El rol de la Corte Constitucional en el Estado contemporáneo (pp. 209-222). Bogotá, D.C.: Legis.

Ramírez, Y. C. (2014). Breve estudio de ilicitud sustancial en el derecho disciplinario colombiano. [Tesis Maestría]. Universidad del Rosario, Bogotá, D.C., Colombia. Disponible en https:// repository.urosario.edu.co/handle/10336/8800

República de Colombia. Congreso de la República. (28 de enero de 2019). Por medio de la cual se expide el código general disciplinario se derogan la ley 734 de 2002 y algunas disposiciones de la ley 1474 de 2011, relacionadas con el derecho disciplinario. [Ley 1952]. DO: 50.850. Disponible en http://www. secretariasenado.gov.co/senado/basedoc/ley_1952_2019. html

República de Colombia. Asamblea Constituyente. (1991). Constitución Política de la República de Colombia. [Const.]. Gaceta Constitucional $\mathrm{N}^{\mathrm{o}}$ 116. Disponible en http://bit.ly/2NA2BRg República de Colombia. Corte Constitucional. (10 de abril de 2019). Exp. D-12556. [Sentencia C-163]. MP: Diana Fajardo Rivera. Disponible en https://www.corteconstitucional.gov.co/ relatoria/2019/C-163-19.htm 
República de Colombia. Corte Constitucional. (28 de marzo de 2019). Exp. D-12849. [Sentencia C-138]. MP: Alejandro Linares Cantillo. Disponible en https://www.corteconstitucional. gov.co/relatoria/2019/C-138-19.htm

República de Colombia. Corte Constitucional. (03 de diciembre de 2018). Exp. T-6839584. [Sentencia T-461]. MP: Carlos Bernal Pulido. Disponible en https://www.corteconstitucional. gov.co/relatoria/2018/T-461-18.htm

República de Colombia. Corte Constitucional. (04 de octubre de 1993). Exp. D-243. [Sentencia C-417]. MP: José Gregorio Hernández Galindo. Disponible en https://www.corteconstitucional.gov.co/relatoria/1993/C-417-93.htm

República de Colombia. Corte Constitucional. (23 de enero de 1996). Exp. No. D-1008. [Sentencia C-022]. MP: Carlos Gaviria Díaz. Disponible en https://www.corteconstitucional.gov.co/ relatoria/1996/C-022-96.htm

República de Colombia. Corte Constitucional. (5 de julio de 2001). Exp. D-3287. [Sentencia C-710]. MP: Jaime Córdoba Triviño. Disponible en https://www.corteconstitucional.gov.co/ relatoria/2001/C-710-01.htm

República de Colombia. Corte Constitucional. (16 de octubre de 2014). Exp. T-3.955.581. [Sentencia SU-768]. MP: Jorge Iván Palacio Palacio. Disponible en https://www.corteconstitucional. gov.co/relatoria/2014/SU768-14.htm

República de Colombia. Corte Constitucional. (18 de noviembre de 2015). Exp. D-10610. [Sentencia C-699]. MP: Alberto Rojas. Disponible en https://www.corteconstitucional.gov.co/ relatoria/2015/c-699-15.htm

Rusinque, C. (2017). El neoconstitucionalismo latinoamericano. En, F. Julián y J. Albarracín (Eds), Lecciones de Derecho Constitucional (Tomo I, pp. 465-512). Bogotá, D.C.: Universidad Externado. 
Sánchez, D. y Llano, J. (2019). Principios constitucionales, generales y procesales en tiempos de víctimas y justicia transicional. Inciso, 21(2), 229-241. https://doi.org/10.18634/incj.21v.2i.988

Santos, M. (2017). Una filosofía para erizos: una aproximación al pensamiento de Ronald Dworkin. En, C. Hernández (Dir.), Dworkin sobre el derecho internacional (pp. 9-58). Bogotá, D.C.: Universidad Libre. Recuperado de https://repository.unilibre.edu.co/bitstream/handle/10901/11468/46\%20 dworkin.pdf?sequence $=1$

Serrano, K. (2019). La respuesta del Estado colombiano a la corrupción desde el derecho penal. Misión Jurídica, 12(17), 261285. https://doi.org/10.25058/1794600X.1052

Stone, A. y Matthews, J. (2013). Proporcionalidad y constitucionalismo. Un enfoque comparativo global. Bogotá, D.C.: Universidad Externado.

Treviño, J. (2020). La influencia de la sociología jurídica estadounidense: de Oliver Wendell Holmes a los Estudios Críticos del Derecho. Bogotá, D.C.: Universidad Externado.

Velasco, N. y Llano, J. V. (2015). Teoría del derecho, neoconstitucionalismo y modelo de Estado constitucional en el contexto colombiano. Novum Jus, 9(2), 49-73. https://doi.org/10.14718/ NovumJus.2015.9.2.2

Maria Stephania Aponte García es Master en Derecho Constitucional y Abogada de la Universidad Libre (Cali, Colombia). Integrante del Grupo de investigación Derecho Constitucional, administrativo y Derecho Internacional Público con categoría A1 en la última convocatoria de Colciencias-Minciencias, línea de investigación Globalización, Derecho Estatal y Derecho Administrativo. Investigadora externa de la facultad de Derecho, Ciencias Políticas y Sociales de la Universidad Libre (Colombia), y docente de la Unidad Central del Valle del Cauca (Uceva, Colombia). https://orcid.org/0000-0003-26422896 
Jairo Vladimir Llano Franco es PH.D. en Derecho de la Universidad Externado de Colombia. Especialista en Antropología Jurídica de la Universidad del Cauca (Colombia). Antropólogo y Becario del Instituto Internacional de Sociología Jurídica de Oñati (España). Líder del Grupo de investigación Derecho Constitucional, Administrativo y Derecho Internacional Público con categoría A1. Investigador Senior (IS) para la más reciente clasificación de Colciencias-Minciencias, línea de investigación Globalización, Derecho Estatal y Derecho Administrativo. Profesor titular de la facultad de Derecho, Ciencias Políticas y Sociales de la Universidad Libre (Colombia). https://orcid. org/0000-0002-4018-5412

Giovanni Sánchez Espinosa es Master y Especialista en Derecho Público de la Universidad Externado de Colombia. Abogado de la Universidad Santiago de Cali (Colombia). Integrante del Grupo de investigación Derecho Constitucional, Administrativo y Derecho Internacional Público con categoría A1. Investigador Junior del convocatorio 833 de 2018-Colciencias, línea de investigación Globalización, Derecho Estatal y Derecho Administrativo, profesor tiempo completo Facultad de Derecho, Ciencias Políticas y Sociales de la Universidad Libre (Colombia). https://orcid.org/0000-0003-4080-8541 